\title{
Smoking cessation advice: the self-reported attitudes and practice of primary health care physicians in a military community, central Saudi Arabia
}

This article was published in the following Dove Press journal:

Patient Preference and Adherence

26 April 2016

Number of times this article has been viewed

\author{
Mohammed AlAteeq' \\ Abdulaziz M Alrashoud ${ }^{2}$ \\ Mohammed Khair ${ }^{2}$ \\ Mahmoud Salam ${ }^{3}$ \\ 'Department of Family Medicine, \\ ${ }^{2}$ College of Medicine, King Saud bin \\ Abdulaziz University for Health \\ Sciences, ${ }^{3}$ King Abdullah International \\ Medical Research Center, Ministry of \\ National Guard Health Affairs, Riyadh, \\ Saudi Arabia
}

Background: Brief advice on smoking cessation from primary health care (PHC) physicians reduces smoking prevalence. However, few studies have investigated the provision of such advice by PHC physicians providing services to military communities. The aim of this study was to evaluate PHC physicians' attitudes toward and practice of delivering smoking cessation advice to smokers in a military community in central Saudi Arabia.

Methods: A self-reported survey of PHC physicians was conducted in 2015 using a previously validated tool. The age, sex, educational level, job title, experience and previous smoking cessation training of each physician was recorded. Attitude (ten statements) and practice (six statements) were evaluated on a five-point Likert scale. Scoring system was applied and percentage mean scores (PMS) were calculated. Descriptive/statistical analyses were applied to identify factors that were significantly associated with a positive attitude and favorable practice (PMS $>65$ each). $P$-values $<0.05$ were considered to be significant.

Results: Response rate was 73/150 (48.6\%), of which equal sex distribution (52\%:48\%) was observed, with a mean age of $35.3 \pm 9.6$ years. General practitioners constituted $71.4 \%$, followed by consultants $(17.9 \%)$ and specialists $(10.7 \%)$. Those with a postgraduate education formed $49.3 \%$, while experience averaged $9.5 \pm 9.2$ years. Approximately $56 \%$ had not attended a smoking cessation educational program in the previous year. Approximately $75 \%$ of physicians had a positive attitude (PMS $=72.4 \pm 11.2$ ), while $64.4 \%$ reported favorable practice (PMS $=65.3 \pm 27.7$ ). Higher education levels were significantly more associated with positive attitude than lower education levels (adj. odds ratio [OR] 95\% confidence interval $[\mathrm{CI}]=17.9$ [1.3-242.3]; adj. $P=0.03$ ). More experienced physicians (adj. OR [95\% CI] =9.5 [1.6-54.6]) and those with positive attitude (adj. OR $[95 \% \mathrm{CI}]=6.1[1.6-23.3]$ ) were more likely to report a favorable practice, compared to the less experienced (adj. $P=0.012)$ and physicians with a negative attitude (adj. $P=0.008)$.

Conclusion: Provision of smoking cessation advice by primary health care physicians serving a military community is significantly associated with their attitude and years of experience. Patients who are seeking smoking cessation advice should be referred to physicians with higher levels of education. Routinely scheduled training on proper delivery of smoking cessation advice may increase physicians' confidence; improve their attitude, and subsequently, their practice. Keywords: smoking cessation advice, primary health care, attitude, practice, Saudi Arabia

\section{Introduction}

Smoking is internationally recognized by the World Health Organization as the most prevalent health problem and a preventable single cause of death. ${ }^{1}$ The Kingdom of Saudi Arabia has unique cultural characteristics that are deeply religious, conservative, traditional, and family oriented. Smoking has been prohibited in the Kingdom
Correspondence: Mahmoud Salam National Biobanking Section, King Center, King Saud bin Abdulaziz University for Health Sciences (Mail Code I5 I5), Ministry of National Guard Health Affairs, Riyadh 22490, Saudi Arabia Tel +966 I 534284644 Email salamma@ngha.med.sa (c) (1) (5) 2016 Alateeq et al. This work is published and licensed by Dove Medical Press limited. The full terms of this license are available at https://www.dovepress.com/terms.php
and incorporate the Creative Commons Attribution - Non Commercial (unported, v3.0) License (http://creativecommons.org/licenses/by-nc/3.0/). By accessing the work you (c)
hereby accept the Terms. Non-commercial uses of the work are permitted without any further permission from Dove Medical Press Limited, provided the work is properly attributed. For permission for commercial use of this work, please see paragraphs 4.2 and 5 of our Terms (https://www.dovepress.com/terms.php). 
since 1926 when King Abdulaziz clearly labeled this habit as unreligious, as it was unhealthy. ${ }^{2}$ Recent studies estimate that about $17.5 \%$ of the Saudi Arabian population consists of smokers. ${ }^{3}$ Although this prevalence varies across various age groups, it was reported that $20 \%-50 \%$ of Saudi smokers start this habit as early as 15 years of age. ${ }^{4}$

The Saudi Arabian authorities have been launching numerous awareness campaigns to discourage smoking. Despite the fact that legislators have issued penalties to restrict smoking in public areas, ${ }^{5}$ the annual local market consumption of various tobacco products is worth US\$ 160 million. ${ }^{6}$ This costly habit is a direct cause of high mortality and morbidity. ${ }^{7,8}$ It cuts off the human lifespan by 13.2 years in males and 14.5 years in females. ${ }^{9}$ Saudi Arabia is one of the seven Gulf Cooperation Council countries where, according to reports, there are 30,000 smoking-related deaths per year and $15 \%$ of total health care costs are spent on the treatment of smoking-related illnesses. ${ }^{10}$

Smoking cessation is a daunting task, yet a demanded objective by the community, primary health care (PHC) practitioners, and smokers themselves. In literature, various approaches have been discussed and implemented, such as individual/group counseling, behavioral therapy, or medications. ${ }^{8}$ Counseling and medications are both effective for treating tobacco dependence, and using them together is more effective than using either one alone. ${ }^{11}$ However, the simplest and most cost-effective primary care method of smoking cessation remains a physicians' advice to quit.

A brief advice on smoking cessation provided by $\mathrm{PHC}$ physicians was found helpful in encouraging smokers to quit. $^{12,13}$ Smoking cessation advice can be a short conversation (0.5-3 minutes) delivered during a routine health consultation to smokers seeking a health service, whether or not they intend to quit. Since these smokers view their physicians as influential advisors, smoking cessation advice raises their awareness on its health consequences and triggers the willingness to engage in further discussion to overcome such a bad habit. Therefore, simple advice is less in depth and more informal than other smoking cessation interventions, as it involves asking patients about their current smoking behaviour, advising them to quit, offering assistance by referring them to a specialist service, and arranging for follow-ups. ${ }^{14,15}$

The attitude and practice of PHC physicians toward smoking cessation advice varies worldwide. An overview of 19 studies conducted in different settings showed that eight studies reported negative beliefs and attitudes. ${ }^{16}$ The most common negative beliefs toward advice were being either time consuming (42\%) or ineffective (38\%). Almost
$22 \%$ of physicians reported a lack of confidence in their ability to discuss smoking with their patients, $18 \%$ felt such discussions were unpleasant, 16\% lacked confidence in their knowledge, and relatively few considered discussing smoking outside of their professional duty $(5 \%)$, or that this intruded upon patients' privacy $(5 \%)$, or that such discussion was inappropriate $(3 \%) .{ }^{16}$

Although the attitude and practice of primary care practitioners toward smoking cessation advice has been assessed in literature, little was investigated in PHC clinics that provide services to military communities. Members of military communities, such as national guards, are expected to abide by a proper nutritional and lifestyle behavior to maintain their physical fitness and health. Smoking cessation among military personnel would likely enhance their physical performance, extend their time on service and reduce sick leave.

\section{Purpose of this study}

The aim of this study was to evaluate the attitude and practice of PHC physicians toward delivering smoking cessation advice to their patients in a military community of central Saudi Arabia. This aim was achieved by: 1) describing various characteristics of physicians, 2) assessing their attitudes and practice toward smoking cessation advice, and 3 ) determining the factors associated with their positive attitude and favorable practice.

\section{Materials and methods Study design}

This is a cross-sectional study, using a self-reported survey.

\section{Study setting}

The Saudi Arabian National Guard, also known as the White Army, founded in 1917, is one of the three major branches of the Armed Forces of the Kingdom of Saudi Arabia. It is under the administrative control of the Ministry of National Guard. Its armed facilities are geographically distributed in the central, eastern, and western regions of the Kingdom.

The Ministry of National Guard-Health Affairs provides health care services to the military community of national guards and their dependants. ${ }^{17}$ In its central region Riyadh, the Ministry of National Guard PHC facilities are distributed across four main centers serving a population of 180,000 . One of these centers (clinics of King Abdulaziz National Guard Housing City) is located in the east quarter of Riyadh, 
where around 150 PHC physicians serve a population of $60,000 \cdot{ }^{18}$ Each patient visits a PHC physician approximately four times per year. The number of patients examined by PHC physicians on a daily basis ranges from 12 to 15, with members of various age groups examined. Almost two thirds are simple cases, whereas $33 \%$ are chronic cases and $7 \%$ are acute/lifesaving cases directly referred to emergency departments.

\section{Study subjects and sampling technique}

The eligibility criteria for enrollment in this study included being a full-time employee at the institution and certified by the Saudi Commission for Health Specialties. PHC physicians with various specialties and levels of education were enrolled in this study. Other PHC workers, such as pharmacists, nurses, and medical students, were excluded.

With a population size of 150 , margin of error of 0.06 and confidence level of $95 \%$, the required sample size was calculated as 97 using the population-based Raosoft Sample Size Calculator (Raosoft, Inc 2004; USA: Windermere/ Seattle, Washington). ${ }^{19}$ For convenience, all PHC physicians were invited to participate in this survey between January and March 2015.

\section{Data collection}

The data collection team constituted two medical students from the Faculty of Medicine, King Saud University, Riyadh. This team was trained by the principal investigator on how to introduce the objectives to the study participants in the targeted setting, present them with the survey forms, and collect their response later in sealed envelopes. Two visits were conducted throughout four clinics with a 1-week window, so that physicians were able to fill the self-reported survey at their own leisure.

The components of the survey were sourced out from prevalidated tools that were utilized by 19 published studies in ten different countries, and presented in one systemic review. ${ }^{16}$ The review coded various aspects of the attitude/ beliefs and displayed them in categories. Based on these categories, a list of attitude and practice statements was generated. Data collection forms consisted of:

- Introductory letter: This section explained the general purpose of the study and provided the contact information of the principal investigator, in case any query was raised.

- Sample characteristics: This section questioned a number of aspects such as sex, age, experience, job title, educational level, and any smoking cessation training that they had received within the previous year.

- Outcome characteristics: This section evaluated the attitude and practice toward administering smoking cessation advice to their patients who are smokers. The attitude domain was assessed through ten statements four positive direction (first, second, seventh, tenth) and six negative direction (third, fourth, fifth, sixth, eighth, ninth) statements. The practice domain was evaluated using six statements, all with negative direction. Attitude and practice statements were responded to by physicians on a five-point Likert scale, and scored according to statement direction. For negative direction statements, scoring was as strongly disagree $=4$, disagree $=3$, neutral $=2$, agree $=1$, and strongly agree $=0$, while in positive direction statements, it was vice versa. The scores of attitudinal and practice statements were summated and converted to percentage mean scores (PMS) in bivariate analysis and then categorized in logistic regression. PMS of attitude domain was categorized as positive attitude $(>65)$ and negative attitude $(\leq 65)$, while in practice domain, it was categorized as favorable $(>65)$ and unfavorable $(\leq 65)$.

A series of validation and reliability tests was applied to the data collection tool. The statements were revised by an expert in social science studies. The cover letter and text were revised by a local editorial service that customized it with locally familiar terms and edited it accordingly. The tool was translated to Arabic and back into English, with minimal variations observed. A pilot test was conducted on a group of ten physicians, in which the questionnaire was administered twice with a 2-week spacing (Cohen's kappa ranged 0.7-0.85) on all statements. In addition, their subjective comments were counted during the pilot test.

\section{Ethical considerations}

The survey was conducted among the participants with an introductory letter and after explaining the purpose of the study. Participation in the study was voluntary and confidential, with the participants being assured that their feedback would not affect their work evaluation, work status, and salary. Participants consented by ticking an agreement to participate statement in the bottom of the cover letter. Since the survey was self-reported and kept in sealed envelopes, no influential bias or stressors were created by the data collection team. This study was approved by the Institutional Review Board of the Ministry of National Guard Health Affairs, Riyadh, Saudi Arabia (Protocol \# 13/024). 


\section{Data analysis}

The Statistical Package for the Social Sciences (Version 22; SPSS Inc., Chicago, IL, USA) was used for data analysis. Categorical data of sample characteristics and responses were illustrated in frequencies and percentages. Test of normal distribution (Shapiro-Wilk: $\mathrm{n}=73, P=0.216$ ) indicated that data were normally distributed. Accordingly, the arithmetic mean was used as a summary statistic for quantitative data. The standard deviation was used as a measure of dispersion. Student's $t$-test (two groups) and one-way analysis of variance (ANOVA) (three or more groups) were used as a test of significance to compare numerical data. Logistic regression analysis was used to determine the significant factors associated with the positive attitude and favorable practice toward administering smoking cessation. For all statistical analyses, a $P$-value $\leq 0.05$ was considered to be significant.

\section{Results}

\section{Sample characteristics}

From the four PHC clinics, 73/150 (48.6\%) participants completed and returned the survey. Most of the study participants were Saudi nationals 70/73 (96\%). An equal sex distribution (52\%:48\%) was observed and participants had a mean \pm standard deviation (SD) age of $35.3 \pm 9$. 6 years. The sample primarily consisted of general practitioners $(71.4 \%)$, followed by consultants (17.9\%) and specialists (10.7\%). Almost half (49.3\%) of the respondents had a post-graduate education, and the average number of years of experience was $9.5 \pm 9.2$ years. More than half $(56 \%)$ of the participants had not attended a smoking cessation educational program during the previous year.

\section{Attitude and practice toward smoking cessation advice}

The overall PMS of attitude toward advising patients on smoking cessation was $72.4 \pm 11.2$, and the overall PMS of practice was $65.3 \pm 27.7$. Positive attitude and favorable practice (PMS $>65$ ) were observed in $75.3 \%$ and $64.4 \%$ of physicians, respectively (Figure1). All physicians agreed that giving brief smoking cessation advice was part of their duties (Table 1). Moreover, $91.8 \%$ agreed that the presence of hospital guidelines and special clinics for smoking cessation encouraged them to provide advice. Approximately threequarters of physicians generally disagreed with the statements that they were not confident or uncomfortable giving such advice. In addition, the majority of physicians generally disagreed that giving such advice was time-consuming or

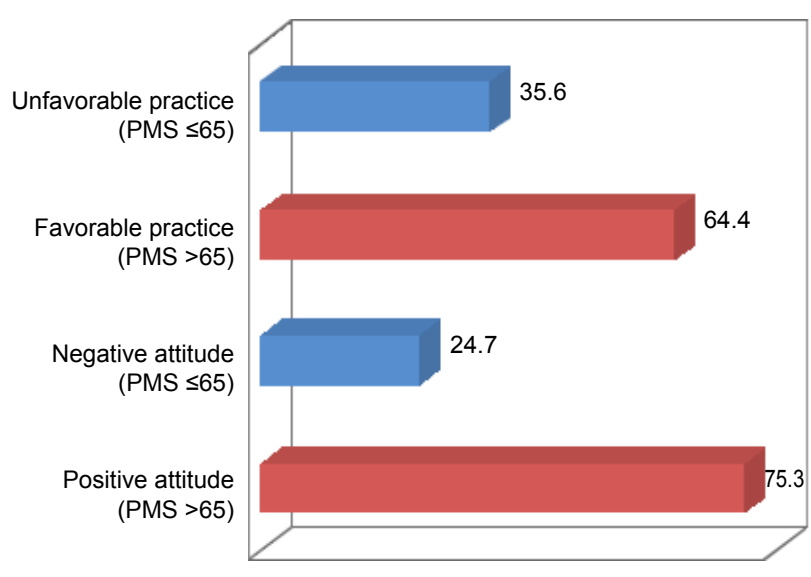

Figure I Percentage distribution of positive/negative attitude and favorable/ unfavorable practice.

Abbreviation: PMS, percentage mean scores.

ineffective. Furthermore, $83.6 \%$ disagreed with the statement that if the physician is a smoker, they should not provide smoking cessation advice (Table 1).

Only $21.9 \%$ of physicians admitted to rarely providing smoking cessation advice to their patients. Physicians reported unfavorable practice when asked whether they gave their patients smoking cessation advice as frequently as needed (79.4\%) or whether they encouraged patients to quit smoking without further action (54.8\%). Favorable practice was observed among physicians who disagreed or strongly disagreed that advice should be provided only if there is sufficient time (56.1\%), if it is relevant to the present complaint $(65.7 \%)$ or if patients request it $(78.1 \%)$ (Table 1$)$.

\section{Factors associated with better attitude and favorable practices}

An initial analysis showed that physicians with a higher level of education had significantly better attitudes (75.7 \pm 11.0$)$ and more favorable practices $(72.2 \pm 27.0)$ than those with lower educational levels $(P=0.011$ and $P=0.034$, respectively) (Table 2). In addition, participants in older age categories showed significantly more favorable practice $(>40$ years $=82.4 \pm 21.7$ and $31-40$ years $=66.0 \pm 26.4)$ than those in younger age categories $(\leq 30$ years $=54.0 \pm 27.3$, $P=0.002$ ) (Table 2). After all variables were adjusted for and all possible confounders were controlled in a logistic regression model, higher educational levels compared with lower educational levels were significantly associated with positive attitude adj. odds ratio $(\mathrm{OR})=17.94,95 \%$ confidence interval $(C I)=1.33-242.3$; adj. $P=0.030$ (Table 3 ). When considering attitude as an exposure of practice, physicians with $>5$ years of experience compared with those with $\leq 5$ years of experience adj. $\mathrm{OR}=9.46,95 \% \mathrm{CI}=1.64-54.55$ and those with a 
Table I Frequency and percentage distribution of physicians' response to attitude and practice statements

\begin{tabular}{|c|c|c|c|c|c|}
\hline & $\begin{array}{l}\text { Strongly disagree } \\
\text { n (\%) }\end{array}$ & $\begin{array}{l}\text { Disagree } \\
\mathrm{n}(\%)\end{array}$ & $\begin{array}{l}\text { Neutral } \\
\text { n (\%) }\end{array}$ & $\begin{array}{l}\text { Agree } \\
\text { n (\%) }\end{array}$ & $\begin{array}{l}\text { Strongly agree } \\
\text { n (\%) }\end{array}$ \\
\hline \multicolumn{6}{|l|}{ Attitude statements } \\
\hline I. Giving brief smoking cessation advice is part of my duties $(+)$ & 0 & 0 & 0 & $29(39.7)$ & $44(60.3)$ \\
\hline 2. It should be given regardless of the present complaint $(+)$ & 0 & $10(13.7)$ & 0 & $39(53.4)$ & $24(32.9)$ \\
\hline 3. Brief smoking cessation advice needs special training $(-)$ & $4(5.5)$ & $21(28.8)$ & $2(2.7)$ & $33(45.2)$ & $13(17.8)$ \\
\hline 4. I don't feel confident in giving brief smoking cessation advice (-) & $18(24.7)$ & $36(49.3)$ & $5(6.8)$ & $14(19.2)$ & 0 \\
\hline 5. I don't feel comfortable giving brief smoking cessation advice (-) & $23(31.5)$ & $33(45.2)$ & $5(6.8)$ & II (I5.I) & $\mathrm{I}(\mathrm{I} .4)$ \\
\hline $\begin{array}{l}\text { 6. If the physician is a smoker, he should not give smoking } \\
\text { cessation advice to his patients }(-)\end{array}$ & $28(38.5)$ & $33(45.2)$ & $2(2.7)$ & $5(6.8)$ & $5(6.8)$ \\
\hline 7. Brief smoking cessation advice is helpful in quitting $(+)$ & $2(2.7)$ & $7(9.6)$ & $2(2.7)$ & $37(50.7)$ & $25(34.3)$ \\
\hline 8. Brief smoking cessation advice is time consuming (-) & $13(17.8)$ & $37(50.7)$ & $2(2.7)$ & $16(21.9)$ & $5(6.9)$ \\
\hline 9. Brief smoking cessation advice is not effective $(-)$ & $25(34.2)$ & $37(50.7)$ & $4(5.5)$ & $6(8.2)$ & $\mathrm{I}(\mathrm{I} .4)$ \\
\hline $\begin{array}{l}\text { 10. Presence of hospital guidelines and special clinics for smoking } \\
\text { cessation will encourage me to provide advice }(+)\end{array}$ & I ( ( .4$)$ & $5(6.8)$ & 0 & $28(38.4)$ & $39(53.4)$ \\
\hline \multicolumn{6}{|l|}{ Practice statements } \\
\hline I. I used to give smoking cessation advice frequently as needed (-) & $2(2.7)$ & $12(16.5)$ & I ( $(1.4)$ & $36(49.3)$ & $22(30.1)$ \\
\hline 2. I rarely provide smoking cessation advice to my patients $(-)$ & $18(24.7)$ & $38(52.1)$ & $\mathrm{I}(\mathrm{l} .4)$ & $14(19.1)$ & $2(2.7)$ \\
\hline 3. I give advice only upon patient request $(-)$ & $16(21.9)$ & $4 \mathrm{I}(56.2)$ & $3(4.1)$ & II (I5.I) & $2(2.7)$ \\
\hline 4. I give advice only if it is relevant to the present complaint (-) & $12(16.4)$ & $36(49.3)$ & I ( $(1.4)$ & $19(26.0)$ & $5(6.9)$ \\
\hline 5. I give advice only if there is enough time $(-)$ & $9(12.3)$ & $32(43.8)$ & 0 & $29(39.7)$ & $3(4.2)$ \\
\hline 6. I usually encourage smokers to quit with no further actions (-) & $4(5.5)$ & $22(30.1)$ & $7(9.6)$ & $38(52.1)$ & $2(2.7)$ \\
\hline
\end{tabular}

Notes: $\mathrm{n}$, frequency; (+), positive direction; (-), negative direction.

Table 2 Sample characteristics compared by the percentage mean scores of attitude and practice

\begin{tabular}{|c|c|c|c|}
\hline & Frequency n (\%) & Attitude $\mathbf{X} \pm \mathbf{S D}$ & Practice $\mathbf{X} \pm \mathbf{S D}$ \\
\hline & $73(100.0)$ & $72.4 \pm 11.2$ & $65.3 \pm 27.7$ \\
\hline \multicolumn{4}{|l|}{ Sex } \\
\hline Male & $38(52.1)$ & $73.9 \pm 11.3$ & $70.6 \pm 25.5$ \\
\hline \multirow[t]{2}{*}{ Female } & 35 (47.9) & $70.7 \pm 11.0$ & $59.5 \pm 29.2$ \\
\hline & & $t=1.21 \mathrm{I}, P=0.230$ & $t=|.73|, P=0.088$ \\
\hline \multicolumn{4}{|l|}{ Age of physician (years) } \\
\hline$\leq 30$ & $29(39.7)$ & $69.1 \pm 10.7$ & $54.0 \pm 27.3$ \\
\hline $31-40$ & $26(35.6)$ & $73.5 \pm 11.5$ & $66.0 \pm 26.4$ \\
\hline \multirow[t]{2}{*}{$>40$} & $18(24.7)$ & $75.9 \pm 10.8$ & $82.4 \pm 21.7$ \\
\hline & & $F=2.345, d f=2, P=0.103$ & $F=6.759, d f=2, P=0.002^{*}$ \\
\hline \multicolumn{4}{|l|}{ Experience (years) } \\
\hline $\mathrm{I}-5$ & $36(49.3)$ & $71.3 \pm 10.9$ & $58.3 \pm 27.5$ \\
\hline $6-10$ & $13(17.8)$ & $72.1 \pm 11.6$ & $67.9 \pm 23.0$ \\
\hline \multirow[t]{2}{*}{ Above 10} & 24 (32.9) & $74.1 \pm 11.7$ & $74.3 \pm 28.6$ \\
\hline & & $F=0.429, d f=2, P=0.653$ & $F=2.566, d f=2, P=0.084$ \\
\hline \multicolumn{4}{|l|}{ Job title } \\
\hline General practitioner & $52(7 \mid .4)$ & $71.3 \pm 10.3$ & $63.8 \pm 27.4$ \\
\hline Specialist & $8(10.7)$ & $72.2 \pm 11.1$ & $54.2 \pm 24.8$ \\
\hline \multirow[t]{2}{*}{ Consultant } & $13(17.9)$ & $76.5 \pm 14.4$ & $78.2 \pm 28.4$ \\
\hline & & $F=1.122, d f=2, P=0.33 \mathrm{I}$ & $F=2.194, d f=2, P=0.118$ \\
\hline \multicolumn{4}{|l|}{ Education level } \\
\hline Bachelor & $37(50.7)$ & $69.1 \pm 10.5$ & $58.6 \pm 27.1$ \\
\hline \multirow[t]{2}{*}{ Post graduate } & $36(49.3)$ & $75.7 \pm \mid 1.01$ & $72.2 \pm 27.0$ \\
\hline & & $t=-2.605, P=0.01 I^{*}$ & $t=-2.156, P=0.034^{*}$ \\
\hline \multicolumn{4}{|c|}{ Smoking education program (past year) } \\
\hline None & $4 \mathrm{I}(56.2)$ & $71.3 \pm 11.9$ & $62.6 \pm 28.3$ \\
\hline \multirow[t]{2}{*}{ Yes } & $32(43.8)$ & $73.8 \pm 10.3$ & $68.8 \pm 27.0$ \\
\hline & & $t=-0.934, P=0.354$ & $t=-0.939, P=0.35 \mathrm{I}$ \\
\hline
\end{tabular}

Notes: $\mathrm{n}$, frequency; $t$, Student's $t$-test; $F$, one-way ANOVA. *Statistically significant at $<0.05$.

Abbreviations: ANOVA, analysis of variance; $\mathrm{Cl}$, confidence interval; $\mathrm{df}$, degrees of freedom; SD, standard deviation; $\mathrm{X}$, mean. 
Table 3 Factors significantly associated with positive attitude and favorable practice

\begin{tabular}{|c|c|c|c|c|c|c|c|c|}
\hline & \multicolumn{8}{|c|}{ Logistic regression } \\
\hline & \multicolumn{4}{|c|}{ Positive attitude } & \multicolumn{4}{|c|}{ Favorable practice } \\
\hline & $\beta$ & SE & $\begin{array}{l}\text { Adj. } \\
\text { P-value }\end{array}$ & $\begin{array}{l}\text { Adj. OR } \\
(95 \% \mathrm{Cl})\end{array}$ & $\beta$ & SE & $\begin{array}{l}\text { Adj. } \\
\text { P-value }\end{array}$ & $\begin{array}{l}\text { Adj. OR } \\
(95 \% \mathrm{Cl})\end{array}$ \\
\hline $\begin{array}{l}\text { Sex } \\
\text { Male versus female }\end{array}$ & 0.47 & 0.60 & 0.430 & $1.61(0.50-5.19)$ & 1.09 & 0.58 & 0.061 & $2.96(0.95-9.23)$ \\
\hline \multicolumn{9}{|l|}{ Experience } \\
\hline $\begin{array}{l}\text { Senior }(>5 \text { years) versus } \\
\text { junior ( } \leq 5 \text { years) }\end{array}$ & -1.80 & 0.95 & 0.058 & $0.17(0.03-1.06)$ & 2.25 & 0.89 & $0.012^{*}$ & $9.46(1.64-54.55)$ \\
\hline \multicolumn{9}{|l|}{ Job title } \\
\hline $\begin{array}{l}\text { Specialists versus general } \\
\text { practitioners }\end{array}$ & -1.29 & 1.18 & 0.273 & $0.28(0.03-2.77)$ & -0.95 & 1.04 & 0.360 & $0.39(0.05-2.97)$ \\
\hline \multicolumn{9}{|l|}{ Education level } \\
\hline Higher versus lower & 2.89 & 1.33 & $0.030^{*}$ & $17.94(1.33-242.3)$ & -0.04 & 0.97 & 0.965 & $0.96(0.14-6.46)$ \\
\hline \multicolumn{9}{|l|}{ Training in past year } \\
\hline Yes versus none & 0.39 & 0.69 & 0.571 & $1.48(0.38-5.7)$ & -0.232 & 0.68 & 0.734 & $0.79(0.2 \mathrm{I}-3.0 \mathrm{I})$ \\
\hline \multicolumn{9}{|l|}{ Attitude } \\
\hline Positive versus negative & - & - & - & - & 1.81 & 0.68 & $0.008^{*}$ & $6.10(1.60-23.25)$ \\
\hline Constant & 0.78 & 0.50 & 0.116 & 2.18 & -1.84 & 0.71 & 0.010 & 0.16 \\
\hline
\end{tabular}

Notes: $\beta$, coefficient of determination. *Statistically significant at $P<0.05$.

Abbreviations: adj., adjusted; $\mathrm{Cl}$, confidence interval; OR, odds ratio; SE, standard error.

positive attitude adj. $\mathrm{OR}=6.10,95 \% \mathrm{CI}=1.60-23.25$ ) were significantly more likely to report favorable practice (adj. $P=0.012$ and adj. $P=0.008$, respectively) (Table 3 ).

\section{Discussion}

The general findings in this study indicate that $75 \%$ of the Saudi PHC physicians in this setting reported a positive attitude (PMS >65) toward advising patients on smoking cessation, whereas favorable practice (PMS >65) was observed in $64 \%$. The attitude of physicians in this study was slightly higher than that reported for Saudi dentists, of whom $62 \%$ reported smoking cessation as an important preventive health measure. ${ }^{20}$ Another study questioned the intention of medical students from a neighboring country (Lebanon) toward administering smoking cessation advice to patients. It showed that their mean score of intention over a ten-point scale was $6.9 \pm 0.3$, or a PMS of $69.0 \pm 3.0$, which is less than what was reported in this study. ${ }^{21}$ In addition, a systematic review noted that among 19 studies, eight conducted on general practitioners and family physicians reported negative beliefs and attitudes toward discussing smoking cessation with their patients. ${ }^{16}$ This entails that although the reported attitude and practice in this setting is slightly better than what was reported in literature, yet there are still some aspects that can be modified and improved.

Physicians with higher levels of education reported a more positive attitude $(P=0.011)$ and favorable practice
$(P=0.034)$ as reflected by the bivariate analysis. After adjusting for covariates, physicians with higher education were 17.9 times more likely to report positive attitude, compared to physicians with lower educational levels. One study recognized the physicians' age as a factor associated with negative attitude. ${ }^{22}$ Authors in this study counted working years as a more reflective measure than age years in terms of the actual work experience in PHC. Accordingly, study findings showed that expert physicians ( $>5$ years on duty) were actually 9.5 times more likely to deliver smoking cessation advice to their patients (adj. $P=0.03$ ), compared to the less-experienced physicians. Literature also reported that physicians are actually missing opportunities to advise smokers to quit due to their lack of educational skills in preventive medicine, including smoking cessation. ${ }^{23}$ Findings in this setting were comparable to a study conducted in eastern Saudi Arabia that showed physicians with longer working experience in PHC centers were significantly less likely to display bad practice regarding smoking cessation. ${ }^{22}$

A significant relationship between attitude and practice was observed in this study. Physicians with positive attitude were six times more likely to exhibit a favorable practice of administering smoking cessation advice to their patients (adj. $P=0.008$ ). A significant relationship has been reported in literature regarding the effect of attitude on practice alone and the effect of attitude/knowledge on practice. ${ }^{24}$ Patients visiting PHCs were actually exposed to the practice (smoking 
cessation advice) of physicians enrolled in this study. Therefore, assessing physicians' attitude, identifying the factors associated with it, and improving them can actually improve their practice of providing smoking cessation advice.

Encouraging smoking reduction in general communities and specifically among military personnel is crucial to sustain their healthy lifestyle and service on duty. Although the majority of study participants agreed that providing brief smoking advice is part of their duties, 63\% admitted that such advice needs special training. Accordingly, scheduled training sessions on proper smoking cessation advice are of great importance to improve such aspects of the attitude. Negative attitudes among physicians may negatively influence their current practice and, thus, it requires attention at the organizational strategic levels. For instance, the PHC strategy of New Zealand's Ministry of Health, similar to that of other countries worldwide, lists reduction in smoking at the top of its list of 13 population health objectives. ${ }^{25}$ Health organizations are expected to align the goals of PHC physicians with the strategic objectives of their institution by increasing awareness on smoking reduction.

\section{Limitations}

The present study had a main limitation which was the substandard sample size that might limit its statistical power and generalizability to other settings. However, the study was conducted in a setting with distinctive characteristics, serving a military community. Although the results of this study might not be generalizable to all health care settings locally or internationally, they can be compared to those of similar institutions serving military communities elsewhere.

Authors of this study focused on assessing the physician's attitude toward administering smoking cessation advice to patients, without assessing the prevalence of smoking among them. Due to the fact that an attitudinal statement, that is, "If the physician is a smoker, he should not give smoking cessation advice to his patients", was present, the authors feared a response or social desirability bias might occur. Self-reported prevalence of smoking by physicians could be probably underreported due to the community's perceived image of doctors, which sees in them healthy role models.

The data collection tool used in the present study was refined from a tool used to assess the outcomes of a systematic review on PHC physicians' attitudes to giving smoking cessation advice. ${ }^{16}$ The tool used in this study is a shorter version and is well structured and thoroughly tested; so, it can serve as a prevalidated tool for future studies. The outcomes in this study can be compared to the outcomes of a smoking cessation educational program offered to PHC physicians in a pre-post interventional study design. This would draw more detailed analyses examining the association between specific aspects of attitude/practice and improving the modifiable factors.

\section{Recommendations}

The personal confidence of PHC physicians directly improves their attitude and can only be attained by training. ${ }^{16}$ Scheduled smoking cessation educational sessions ensure all physicians are updated with more effective smoking reduction methods. In addition, communication skills can only be refined by their personal experience and interaction with their visiting patients. Accordingly, hospital administrators are encouraged to spread the culture of delivering smoking cessation advice among physicians as part of their routine practice.

\section{Conclusion}

The provision of smoking cessation advice by PHC physicians serving a military community is significantly associated with the physicians' attitudes, educational levels and years of experience. Routinely scheduled training on proper delivery of smoking cessation advice may increase physicians' confidence and improve their attitude and, subsequently, their practice. Our findings suggest that patients seeking smoking cessation advice should be referred to physicians with higher educational levels.

\section{Acknowledgments}

This study was initiated and funded by King Abdullah International Medical Research Center, King Saud bin Abdulaziz University for Health Sciences, Riyadh, Saudi Arabia. The authors would like to thank the research office and the institutional review board for their support. The efforts of the department of family medicine are appreciated. Special thanks to Ms AlAnoud Hasher, the promotional coordinator from the strategy and business development section, who coordinated the language and scientific editing between the authors and the Macmillan Science Communication.

\section{Author contributions}

MA, AMA, and MK conceptualized and designed the study. AMA and MK obtained data and supervised the conduct of the study. MS was responsible for the quality control, and provided statistical advice on study design, analyzed the data and drafted the manuscript. All authors contributed substantially to its revision as submitted, gave final approval and agree to be accountable for all aspects of the work. 


\section{Disclosure}

The authors report no conflicts of interest in this work.

\section{References}

1. World Health Organization. WHO Report on the Global Tobacco Epidemic, 2009: Implementing Smoke-free Environments. Geneva: World Health Organization; 2009. Available from: http://www.who. int/tobacco/mpower/2009/en/. Accessed December 15, 2015.

2. Tripp H, North P. Culture Shock! Saudi Arabia. Kuperard: Marshall Cavendish Editions; 2003:28.

3. Bassiony MM. Smoking in Saudi Arabia. Saudi Med J. 2009;30(7): 876-881.

4. Al-Faris E. Smoking habits of secondary school boys in rural Riyadh. Public Health. 1995;109(1):47-55.

5. Almotairi H. Smoking in Saudi Arabia and its control measures. $\mathrm{Br} J$ Human Soc Sci. 2012;5(2):69-75.

6. Ministry of Finance and National Economy. Foreign Trade Statistics in Saudi Arabia, 1985-1995. Riyadh (KSA): Ministry of Finance and National Economy; 1996:15. Available from: https://www.imf.org/ external/pubs/ft/scr/2012/cr12272.pdf. Accessed December 20, 2015.

7. American Cancer Society. Cancer Facts and Figures 2012. Atlanta: American Cancer Society; 2012.

8. American Lung Association. Trends in Tobacco Use; 2011. Available from: www.lungusa.org/finding-cures/our-research/trend-reports/ Tobacco-Trend-Report.pdf. Accessed December 1, 2015.

9. Control CfD, Prevention. Cigarette smoking among adults - United States, 2006. MMWR. 2007;56(44):1157.

10. Al Turki K, Al Baghli N, Al Ghamdi A, El Zubaier A, Al Ghamdi R, Alameer M. Prevalence of current smoking in Eastern province, Saudi Arabia. East Mediterr Health J. 2010;16(6):671-676.

11. Fiore M. Treating Tobacco Use and Dependence: 2008 Update: Clinical Practice Guideline. Darby: Diane Publishing; 2008.

12. Kottke TE, Battista RN, DeFriese GH, Brekke ML. Attributes of successful smoking cessation interventions in medical practice: a metaanalysis of 39 controlled trials. JAMA. 1988;259(19):2882-2889.

13. Stead LF, Bergson G, Lancaster T. Physician advice for smoking cessation. Cochrane Database Syst Rev. 2008;16(2):CD000165.
14. West R, McNeill A, Raw M. Smoking cessation guidelines for health professionals: an update. Thorax. 2000;55(12):987-999.

15. Powell K, Thurston M. Commissioning Training for Behavior Change Interventions: Guidelines for Best Practice. Chester: University of Chester; 2008.

16. Vogt F, Hall S, Marteau TM. General practitioners' and family physicians' negative beliefs and attitudes towards discussing smoking cessation with patients: a systematic review. Addiction. 2005;100(10):1423-1431.

17. Alanazi MQ, Al-Jeraisy MI, Salam M. Comparative outcome analysis of home-initiated non-medical interventions among toddlers with orally ingested substances. Ital J Pediatr. 2015;41(1):1-9.

18. Mohammed A, Rowaily A. Prevalence of uncorrected refractive errors among adolescents at King Abdul-Aziz Medical City, Riyadh, Saudi Arabia. J Clin Ophthalmol. 2010;1:1-4.

19. In R. Sample size calculator. 2010. Raosoft, Inc. Available from http:// www.raosoft.com/samplesize.html. Accessed December 15, 2015.

20. Awan K, Hammam M, Warnakulasuriya S. Knowledge and attitude of tobacco use and cessation among dental professionals. Saudi Dent J. 2015:27(2):99-104.

21. Jradi H, Wewers ME, Pirie PP, Binkley PF, Ferketich AK. Lebanese medical students' intention to deliver smoking cessation advice. J Epidemiol Global Health. 2015;5(2):117-123.

22. Al-Turkstani AHM, Alkail BA, Hegazy AA, Asiri SI. Knowledge, attitude, and practice among primary health-care physicians toward smoking cessation in Makkah, Saudi Arabia. Int J Med Sci Public Health. 2016;5(7);1-11.

23. Cornuz J, Humair J-P, Seematter L, Stoianov R, van Melle G, Stalder H, et al. Efficacy of resident training in smoking cessation: a randomized, controlled trial of a program based on application of behavioral theory and practice with standardized patients. Ann Intern Med. 2002;136(6):429-437.

24. Sabouhi F, Babaee S, Naji H, Zade AH. Knowledge, awareness, attitudes and practice about hypertension in hypertensive patients referring to public health care centers in Khoor \& Biabanak 2009. Iran J Nurs Midwifery Res. 2011;16(1):35.

25. King A. The Primary Health Care Strategy. Wellington: Ministry of Health; 2001. Available from: https://www.health.govt.nz/system/files/ documents/publications/phcstrat.pdf. Accessed December 15, 2015.
Patient Preference and Adherence

\section{Publish your work in this journal}

Patient Preference and Adherence is an international, peer-reviewed, open access journal that focuses on the growing importance of patient preference and adherence throughout the therapeutic continuum. Patient satisfaction, acceptability, quality of life, compliance, persistence and their role in developing new therapeutic modalities and compounds to optimize

\section{Dovepress}

clinical outcomes for existing disease states are major areas of interest for the journal. This journal has been accepted for indexing on PubMed Central. The manuscript management system is completely online and includes a very quick and fair peer-review system, which is all easy to use. Visit http://www. dovepress.com/testimonials.php to read real quotes from published authors. 